Laboratorio de Arte,4-1991 http://dx.doi.org/10.12795/LA.1991.i04.21

\title{
UNA ESCULTURA DE CAYETANO DE ACOSTA EN EL CONVENTO DEL CARMEN DE SAN FERNANDO (CÁDIZ)
}

por Luis Francisco Martínez Montiel

La orden carmelita se instalaría en la bahía gaditana a finales del siglo XVII. La saturación de conventos que en aquel momento sufría la capital hizo que los primeros carmelitas descalzos se establecieran en la Real Isla de León, muy cerca del camino que conducía a Cádiz '. La comunidad, desde el momento de sú primera fundación en 1680, trabajaría por conseguir mejores terrenos para su definitivo establecimiento. El apoyo de una población en constante crecimiento y las generosas donaciones del comerciante genovés Don Limbiano Escalloso pronto hicieron posible las nuevas trazas del Convento. Las obras, dirigidas por el maestro Juan de San Román, se prolongarían durante todo el primer tercio del siglo XVIII. Así, en 1733, se inauguraba solemnemente el templo, dándose a partir de ese momento un fuerte impulso final a las labores ornamentales de todo el Convento ${ }^{2}$.

La fachada de la iglesia, estructurada en dos cuerpos y tres calles, quedaría concluida en la década de 1740. En la central se sitúa el vano de ingreso,

1. Sobre la fundación del Convento de carmelitas descalzos en la Real Isla de León véase el manuscrito hallado en I835 en la Iglesia parroquial de Paterna de la Rivera. Parte de éste es recogido por CLAVIJO Y CLAVIJO, Salvador: La ciudad de San Fernando. Historia y Espíritu. T. I. San Fernando, 1960, pp. 225 y ss.

2. Para conocer el proceso constructivo y omamental del Convento de carmelitas consúltese: LÓPEZ GARRIDO, José Luis; MARTÍNEZ MONTIEL, Luis Francisco; RAMÍREZ MALO, Felicitas: Guia histórico-artistica de San Fernando. San Fernando, 1989, pp. 96-100. 
compuesto el módulo por un arco de medio punto, en cuya clave se colocó el escudo carmelita. Sobre las pilastras que flanquean la entrada corre un entablamento rematado por frontón triangular partido. El centro de esta composición lo ocupa una hornacina avenerada para la que el escultor de origen portugués Cayetano de Acosta realizó en mármol la imagen de Nuestra Señora del Carmen.

Con la documentación de esta obra la labor escultórica de Acosta, relegada a un segundo plano por su importancia como retablista, puede ser analizada y valorada en su justa medida. De hecho, la imagen de Nuestra Señora del Carmen de la fachada de la iglesia del Convento de Descalzos de la ciudad de San Fernando en Cádiz demuestra la categoría de Acosta como escultor.

Tras una primera fase sevillana recientemente estudiada por Pleguezuelo, el escultor se instala en Cádiz, donde residiría entre los años finales de la década de 1730 y 1750 aproximadamente. Hasta este momento, de la actividad de Cayetano de Acosta en Cádiz, a excepción de los trabajos realizados para la catedral gaditana, apenas existía constancia ${ }^{3}$. Sin embargo, la gran calidad y la importancia de sus escasas obras documentadas hacen posible afirmar que su trabajo fue muy bien considerado por sus contemporáneos y que lo que hoy se atribuye a su mano no es más que una pequeña parte de lo que en realidad él y su taller trabajaron en las provincias de Sevilla y Cádiz.

La escultura de la Virgen del Carmen se contrataba en la Real Isla de León, ante el escribano público Don Alvaro de la Torre Canales. El 19 de mayo de 1748 Cayetano de Acosta firmaba con el padre prior Fray Juan de los Reyes "la obligación de hazer una imagen" para el convento carmelita ${ }^{4}$. Según el protocolo, Acosta se comprometía a tenerla concluida en el plazo de cuatro meses contados desde la fecha del contrato. Asimismo, se obligaba a labrarla con sus propias manos, aclarando que de hacerla su taller sería realizada con su asistencia a los oficiales elegidos.

La obligación recoge otra serie de condiciones, entre las que obviamente se incluye la necesidad de adecuarla en tamaño al hueco abierto en la fachada de la iglesia. También se insertaba en el documento la forma en que debía representarse a la Virgen. Concretamente se dice que tendría que aparecer "Ntra. madre y $S$. del Carmen, con un Niño en los brazos y con una nube con tres serafines que le

3. Los últimos trabajos publicados sobre Cayetano de Acosta facilitan la comprensión tanto de su vida como de parte de su obra. En este sentido son realmente interesantes los artículos publicados por PLEGUEZUELO HERNÁNDEZ, Alfonso:

- "Cayetano da Costa, escultor en piedra y la remodelación de la Alameda de Hércules en 1764-1765", en Resúmenes de Actas del III Congreso de C.E.H.A. Sevilla, 1980, pp. 46 y ss.

- "Sobre Cayetano de Acosta, escultor en piedra". En Arte Sevillano. N.- 2. Sevilla, 1982, pp. 35 y ss.

- "Aportaciones a la biografía y obra de Cayetano de Acosta: la fase gadiana". Boletín de Arte y Arqueología Valladolid, 1988, pp. 483 y ss.

4. Archivo de Protocolos Notariales de San Fernando. Legajo n. ${ }^{2}$ 14. Folios 81 a 82 vto. 
sirvan de trono a sus pies". Por último, Cayetano de Acosta se comprometía a entregarla acabada y "sin fealdad" alguna, pues de lo contrario habría de hacerla de nuevo a su costa.

Por su parte, el Convento, a través de su prior, se obligaba a entregar rápidamente en la ciudad de Cádiz la piedra de mármol necesaria, del largo, ancho y grueso conveniente para poder culminar la imagen, así como a pagar los cien pesos escudos de quince reales de vellón cada uno en que se había estipulado la obra. De ellos, veinticinco los cobraba Acosta con la firma del contrato, otros tantos el día de San Juan del mismo año, y los restantes cincuenta a la conclusión, aunque no hubiesen transcurrido los cuatro meses reseñados en la obligación.

La escultura, pese a que fue tallada por el escultor para ser observada desde abajo, presenta una excepcional y cuidada labor de talla. La Virgen de bella factura mira dulcemente al Niño que sostiene en su brazo izquierdo. Su rostro, perfectamente cuidado, puede relacionarse con el ejecutado casi veinte años después en la Inmaculada que hoy se halla en el Palacio Arzobispal de Sevilla. Sus peinados son muy similares, dejando que la cabellera dividida al centro muestre los lóbulos de la oreja, característica esta que se repite en casi todas las obras del escultor ${ }^{5}$. Asimismo, es muy similar la inclinación de la cabeza, que en la Virgen del Carmen pone en relación a la Madre con el Niño. Este, que juega con el escapulario en acusado escorzo, es llevado por su Madre sin aparente esfuerzo. En su mano derecha lleva la Virgen un sencillo cetro realizado en bronce, material utilizado también en la corona ${ }^{6}$.

Igualmente, son de destacar los querubines que forman el pedestal de la imagen. Estos con sus mofletes inflados y sus barbillas divididas nos confirman de nuevo la relación con la figura del Palacio Arzobispal sevillano y con otra posible obra del escultor, como es el aguamanil del convento de Santa María de Cádiz.

El análisis detallado de la escultura nos permite descubrir en ella una cuidada talla y un interesante estudio compositivo. Acosta, consciente de que la imagen sería observada desde un solo foco visual, intenta eliminar la excesiva frontalidad que ello podría producir en su obra. Por esto, y para evitar la sensación de planismo, contrapesa la configuración de las líneas básicas de la imagen. Así, utiliza la línea serpenteante que produce el revoloteo del manto para contrarrestar la verticalidad del escapulario. Gracias a este recurso consigue además enriquecer el único punto de vista del espectador, dando la impresión de que la figura

5. Esta imagen fue documentada por VALDIVIESO GONZÁLEZ, Enrique: "Una Inmaculada inédita de Cayetano de Acosta", en Archivo Hispalense n.. ${ }^{196}$. Sevilla, 1981, pp. 143-145.

6. Tanto el cetro como la corona están perjudicando la conservación de la imagen, pues están produciendo manchas de óxido que afean considerablemente la talla. 
ocupa varios planos. A ello también contribuyen la situación del brazo derecho, la colocación adelantada del pie izquierdo y la flexión de la pierna derecha con la consiguiente elevación del hombro contrario, lo que da a la escultura una gran movilidad. Este dinamismo permite relacionarla con la escultura de la Fama que esculpiera para coronar el frontón de la antigua Fábrica de Tabacos y que según la petición del "aparexo real o inxenio" que don Juan Hierro, su contador principal, hizo al Cabildo catedralicio, fue instalada en enero de $1757^{7}$.

Gracias a esta imagen de Ntra. Sra. del Carmen se incrementa el catálogo de Cayetano de Acosta en su fase gaditana. Por otra parte, esta nueva obra documentada puede servir para reforzar algunas atribuciones caso del ya citado aguamanil del convento de Santa María del que, si bien no hay referencias escritas que permitan afirmar su autoría, sí que posee similitudes evidentes con la ahora presentada ${ }^{8}$. Además, la documentación de una obra de Cayetano de Acosta al margen de su trabajo en la catedral gaditana puede servir de punto de partida a una nueva serie de atribuciones, pues es evidente que en Cádiz muchas de las obras escultóricas de este período poseen las características tipológicas de su producción y que si aún permanecen en el anonimato es por haberse restringido excesivamente el campo de estudio de Cayetano de Acosta al contexto catedralicio. Es por tanto lógico pensar que un análisis más exhaustivo de nuestros archivos confirmará las atribuciones de numerosas esculturas que en estos momentos tan sólo se adivinan como obras de Acosta.

7. La petición por parte del contador de la Fábrica de Tabacos de un "aparexo real o inxenio con todos sus pertrechos, para colocar en la portada de su edificio una estatua gigantesca de primorosa lavor de Marmol blanco, que significa la fama" se encuentra en el Archivo de la Catedral de Sevilla. Autos Capitulares del 21 de enero de 1757. Folio 22 vto. Esta obra ha sido estudiada por CARRERA SANABRIA, Manuel:

- "Unas obras desconocidas del escultor Cayetano de Acosta", en Archivo Hispalense T. V. n.. 12. Sevilla, 1945 , pp. 27 y ss.

- "Más sobre Cayetano de Acosta y sus obras en la Fábrica de Tabacos de Sevilla", en Archivo Hispalense. T. VIII, n. ${ }^{8} 21$. Sevilla, 1947, pp. 393 y ss.

8. Este aguamanil fue publicado por PEMÁN, César: El arte en Cádiz. Cádiz, 1930. Asimismo, PLEGuEZUELO HERNÁNDEZ, Alfonso, atribuye esta obra a Cayetano de Acosta en Aportaciones... p. 493. Igualmente lo hacen ALONSO DE LA SIERRA FERNÁNDEZ, Juan y Lorenzo en su Guía artística de Cádiz. Cádiz, 1987, p. 71. Las evidentes semejanzas que presentan las tallas de los ángeles y de la Inmaculada del aguamanil con la Virgen del Carmen refuerzan esta hipótesis. 


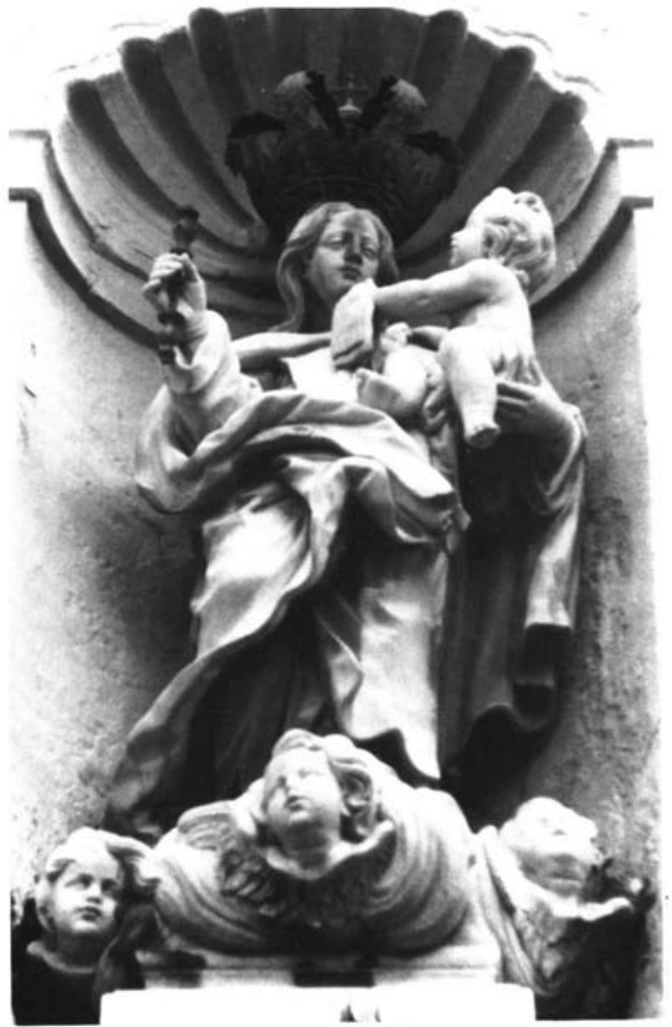

San Fermando (Cádiz). Convento de Carmelitas Descalzos. Virgen del Carmen. Cayetano de Acosta. 1748. 